\title{
Rare Earths and the Balance Problem
}

\author{
Koen Binnemans $\cdot$ Peter Tom Jones
}

Published online: 8 January 2015

(C) The Minerals, Metals \& Materials Society (TMS) 2015

\begin{abstract}
Maintaining the balance between the demand by the economic markets and the natural abundance of the rare-earth elements (REEs) in ores constitutes a major challenge for manufacturers of these elements. This is the so-called balance problem (or balancing problem). The ideal situation is a perfect match between the demand and (production) supply of REEs, so that there are no surpluses of any of the REEs. The balance problem implicates that the rare-earth industry has to either find new applications for REEs that are available in excess, or needs to search for substitutions for REEs that have limited availability and that are high in demand. Different solutions are proposed to solve the balance problem: diversification of REE resources, recycling and urban/landfill mining, substitution, reduced use and new high-volume applications. No single solution can solve the balance problem, but a combination of different strategies can. It is illustrated that the issue of thorium in REE ores is also directly related to the balance problem: presently, thorium is considered as radioactive waste, but this waste could be turned into a valuable resource by using thorium in a thorium-based nuclear fuel cycle.
\end{abstract}

Keywords Lanthanides - Permanent magnets - Rare earths $\cdot$ Recycling $\cdot$ Substitution $\cdot$ Thorium

\footnotetext{
K. Binnemans $(\bowtie)$

Department of Chemistry, KU Leuven, Celestijnenlaan 200F, P.O. Box 2404, 3001 Heverlee, Belgium

e-mail: Koen.Binnemans@ chem.kuleuven.be

P. T. Jones

Department of Materials Engineering, KU Leuven, Kasteelpark Arenberg 44, P.O. Box 2450, 3001 Heverlee, Belgium
}

\section{Introduction}

The global annual production of rare earths or rare-earth elements (REEs) is typically expressed in tonnes of rareearth oxides (REOs). At present, the estimated yearly total production of REOs is about 125,000 tonnes, although accurate production numbers are very difficult, if not impossible, to obtain. However, these total production numbers give no indication about the availability of the individual REEs. First of all, not the total amount of REE ores mined is of importance, but rather the total amount of REE concentrate separated in the different individual REEs. For some applications, such as mischmetal, no separated REEs are required. Secondly, the REEs are not present in equal amounts in the REE ores, due to differences in the natural abundances of these elements. The general trend in the natural abundance of the rare earths is that the elements become scarcer with increasing atomic number $Z$; as the abundances decrease over the lanthanide series, the heavy rare-earth elements (HREEs) are much less abundant than the light rare-earth elements (LREEs) [1]. Additionally, elements with an even atomic number $Z$ are more abundant than elements with an odd atomic number (Oddo-Harkins rule). For example, cerium $(Z=58)$ is more abundant with respect to its neighbours lanthanum $(Z=57)$ and praseodymium $(Z=59)$. Cerium is the dominating rare-earth element in LREE-rich ores (bastnäsite and monazite), while yttrium is the main rare-earth element in HREE-rich ores (xenotime and ion-adsorption ores).

The availability of the individual REEs is of concern for applications that require the use of pure REEs, such as phosphors and permanent magnets. If the REEs that are required for high-volume applications have a low natural abundance, the minimum quantity of REE concentrate that needs to be processed and separated is that quantity that 
will produce at least the amount of REEs required for these critical applications. As a consequence, some REEs will be produced in larger quantities than required by the REE market and, subsequently, these elements need to be stockpiled, which comes at a cost. The balance between the demand by the economic markets and the natural abundances of the REEs in ores is a major problem for manufacturers of these elements [2]. This is the so-called balance problem (or balancing problem) [3, 4]. The ideal situation is a perfect match between the demand and (production) supply of REEs, so that there are no surpluses of any of the individual REEs. This would result in the lowest market price for any of the REEs, because the production costs are shared by all rare-earth elements. Unfortunately, a market in balance is very difficult to achieve, because of changes in demand due to technological evolutions in applications. The result is a sometimes very high demand of a REE that is a minor constituent in the ore (such as dysprosium), while the demand of the major constituent (such as yttrium) is much lower. The size of the REE market is different in terms of value and volume. For instance, phosphors are a very important application of REEs in terms of value (1/3 of the REE market), but they are a rather modest application in terms of volume (about $7 \%$ ). The balance problem is related to the volumes of the individual REEs consumed.

For the REE industry the balance problem is a more important issue than the availability of REE resources, not to say that it is the most important issue facing the REE industry. This paper gives an in-depth analysis of the balance problem and offers several possible mitigation options.

\section{History of the Balance Problem}

The balance problem became an issue as soon as purified REEs started to being used in applications. In contrast, older applications of REEs consumed mixtures of REEs and separation into pure single elements was not required. A good example is mischmetal, which is an alloy of LREEs, with the REEs appearing in the same atomic ratios as they occur in the REE ore minerals. Also for other older applications such as polishing powders or fluid cracking catalysts no pure REEs had to be used. Hence, all REEs that were produced could be fully consumed.

The first application of pure REEs was the use of europium as active component of the red cathodoluminescent phosphors in colour television screens (first $\mathrm{YVO}_{4}: \mathrm{Eu}^{3+}$, later $\mathrm{Y}_{2} \mathrm{O}_{2} \mathrm{~S}: \mathrm{Eu}^{3+}$ ). In the mid-1960s and the early 1970s, europium was the most critical REE because it has a low natural abundance and it was high in demand for the production of these red phosphors. In that period, nearly all of the global supply of europium was produced from the bastnäsite ore of the Mountain Pass mine in California. In fact, the Mountain Pass mine was in that period operated mainly for the production of europium. The bastnäsite of the Mountain Pass mine contains only about $0.1 \mathrm{wt} \%$ europium. The low concentrations of europium implied that large surpluses of the LREEs were produced and needed to be stockpiled: to obtain 1 tonne of $\mathrm{Eu}_{2} \mathrm{O}_{3}$ from bastnäsite, one had to excavate an amount of REE ores that contained 300 tonnes of $\mathrm{La}_{2} \mathrm{O}_{3}, 450$ tonnes of $\mathrm{CeO}_{2}, 38$ tonnes of $\operatorname{Pr}_{6} \mathrm{O}_{11}$, 118 tonnes of $\mathrm{Nd}_{2} \mathrm{O}_{3}, 7.3$ tonnes of $\mathrm{Sm}_{2} \mathrm{O}_{3}, 1.4$ tonnes of $\mathrm{Gd}_{2} \mathrm{O}_{3}$ and 0.9 tonnes of $\mathrm{Y}_{2} \mathrm{O}_{3}$ [5]. In this context it should be mentioned that it is possible to selectively remove europium from mixtures of REEs by reduction of europium(III) to europium(II), for instance by chemical reduction with zinc amalgam or by electrochemical reduction.

In the 1970 and 1980s, samarium was the most critical REE because of its use in samarium-cobalt permanent magnets. At that time, the production of samarium-cobalt magnets was limited by the availability of $\mathrm{Sm}_{2} \mathrm{O}_{3}$ on the market. However, the share of samarium-cobalt magnets in the permanent magnet market is at present $<2 \%$, and an excess of samarium is being produced. Before 1985, there were no industrial applications for dysprosium, and neodymium metal was not produced on an industrial scale. At that time, it could not be predicted that less than 30 years later, neodymium and dysprosium would be high in demand for neodymium-iron-boron magnets. With respect to holmium, thulium, ytterbium and lutetium no high-volume applications currently exist.

Due to the balance problem, there has also been a shift in the types of REE ores used. Until the 1960s, monazite was the main ore (monazite era). For a long time the REEs were just a by-product of the production of thorium which was used for the manufacturing of incandescent gas mantles. In the 1960s, bastnäsite became the most important REE ore, with the Mountain Pass mine in California as the main production site (Mountain Pass era). Bastnäsite was ideal to cover the increasing needs of lanthanum and cerium, as well as to fulfil the demand of europium. Gradually, monazite was favoured again because of its higher content of HREEs and yttrium. The steadily increasing demand of yttrium (mainly for its use in lamp phosphors and yttria-stabilised zirconia) implied that also the yttriumrich phosphate xenotime was processed as a REE ore. From the end of the 1980s onwards, the HREE-rich ion-adsorption ores (laterite clays) from southern China became the most important resource for yttrium and the HREEs.

\section{Current Market Situation and Evolution in the Future}

At present the LREE market is driven by the demand for neodymium for neodymium-iron-boron (NdFeB) magnets 
[6]. This means that sufficient quantities of REE ores have to be mined to meet the demand of neodymium. Since the natural abundance of neodymium in the LREE ores is relatively low, cerium, praseodymium and samarium are produced in excess, and have to be stockpiled. The lanthanum market is in balance, thanks to its use in nickel metal hydride batteries and optical glasses. A few years ago, it was nevertheless predicted that there would be a sharp decline in the use of nickel metal hydride batteries due to the increased use of lithium-ion batteries. However, there are still many safety issues related with these lithiumion batteries; overheating of the organic electrolytes can cause ignition of lithium-ion batteries. For these reasons, it is likely that nickel metal hydride batteries will continue to be used for several years to come in high-power applications such as electric vehicles.

The HREEs are produced in much smaller quantities than the LREEs, so that the balance problem is a more important issue for the LREE market than for the HREE market. At present, the HREE market is driven by the demand for dysprosium, which is used to increase to hightemperature performance and resistance to demagnetisation (i.e. the intrinsic coercivity) of $\mathrm{NdFeB}$ magnets. The supply equals the demand for europium, yttrium and erbium. There is a shortage of terbium, but this problem can still be solved by the use of stockpiles. Gadolinium, holmium, thulium, ytterbium and lutetium are produced in excess and are stockpiled. This stockpiling is not a major issue in terms of volumes, but it causes a loss of potential profit for the REE producers.

It is evident that the REE market is a rapidly changing market. New applications as well as the sudden disappearance of well-established applications could bring the REE market out of balance. Although the present REE market is driven by the demand for neodymium and dysprosium, this could rapidly change, as shown by the historical evolutions in the REE markets. Although there is currently an oversupply of gadolinium, this global excess could turn into a shortage if magnetic refrigerators would be mass-produced $[7,8]$. It must be admitted that present research activities in the field of magnetic refrigerators are focusing on the development of REE-free materials with a large magnetocaloric effect [9]. Given the fact that kilogramme quantities of gadolinium are required for the construction of one magnetic refrigerator, it is not realistic to assume that such devices would be mass-produced; there is simply not enough gadolinium available in the world to achieve this goal.

It is very likely that within the next years a dramatic change will occur in the lamp phosphor market that might cause an imbalance of the HREE market. At present, europium, terbium and yttrium are considered as three of the five most critical rare earths (the other two being neodymium and dysprosium) because of their use in the red lamp phosphor
$\mathrm{Y}_{2} \mathrm{O}_{3}: \mathrm{Eu}^{3+}$ (YOX), the green lamp phosphors $\mathrm{LaPO}_{4}$ :$\mathrm{Ce}^{3+}, \mathrm{Tb}^{3+} \quad$ (LAP), (Gd,Mg) $\mathrm{B}_{5} \mathrm{O}_{12}: \mathrm{Ce}^{3+}, \mathrm{Tb}^{3+} \quad$ (CBT), $(\mathrm{Ce}, \mathrm{Tb}) \mathrm{MgAl}_{11} \mathrm{O}_{19}$ (CAT) and the blue phosphor BaM$\mathrm{gAl}_{10} \mathrm{O}_{17}: \mathrm{Eu}^{2+}$ (BAM) in fluorescent lamps and compact fluorescent lamps (energy-saving lamps) [10]. However, the fluorescent lamps market is rapidly shrinking due to the increasing success of the light-emitting diodes (LEDs). $\mathrm{Y}_{3} \mathrm{Al}_{5} \mathrm{O}_{12}$ (YAG) doped with about $0.003 \% \mathrm{Ce}^{3+}$ is still heavily in use as a yellow phosphor for white-light LEDs [11], but many types of LEDs do not contain rare earths at all; they produce white light by a combination of red, green and blue LEDs standing in close proximity to each other, similarly to the red-green-blue pixels in old-fashioned cathode-ray tubes. This change from fluorescent lamps to LEDs will make the conventional lamp phosphors largely obsolete. The lamp phosphor $\mathrm{Y}_{2} \mathrm{O}_{3}: \mathrm{Eu}^{3+}$ is by far the most important application of europium. Smaller quantities of luminescent europium compounds are used in safety markers, for instance in the luminescent inks of EURO banknotes. As a consequence of the reduced demand for europium, one may expect an oversupply of this element. However, an oversupply of europium is less of an issue than an oversupply of cerium, since the global production volumes of europium are much smaller than those of cerium. LED lighting systems driven by an alternating current (AC) source that are currently produced in Taiwan and China use phosphors with long decay times based on europium (either $\mathrm{Eu}^{3+}$ or $\mathrm{Eu}^{2+}$ ). These AC LEDs are $25 \%$ more efficient than conventional LEDs. It might be anticipated that they will replace to a large extent the conventional LEDs within 5-10 years, leading to a renewed demand for europium. Long-persistence phosphors containing $\mathrm{Eu}^{2+}$ and $\mathrm{Dy}^{3+}$ are being used for security marking and road marking. This could create a novel demand for europium (and dysprosium). For terbium, it is much easier to find alternative applications than europium because applications of terbium are not restricted to luminescent materials. Terbium can substitute for dysprosium in $\mathrm{NdFeB}$ permanent magnets (vide infra). Likewise, other applications than lamp phosphors are possible for yttrium, since yttrium is a very useful element for the preparation of high-tech ceramic materials, for instance, yttria-stabilised zirconia. Remote-phosphor LEDs form an emerging application of yttrium and cerium. In these LEDs, the phosphor in the form of the yellow phosphor $\mathrm{Y}_{3} \mathrm{Al}_{5} \mathrm{O}_{12}$ :$\mathrm{Ce}^{3+}$ is located at a distance from the LED [12], and they can contain an amount of phosphor that is comparable with compact fluorescent lamps or fluorescent lamps.

\section{How to Solve the Balance Problem?}

Increasing the overall REE production to meet the highest demand of any REE and to stockpile the other REEs with lower demand, seems to be an obvious solution for the 
balance problem. However, this will increase the overall price of the REEs, due to the extra costs for separating the REE mixtures and stockpiling the REEs produced in excess of the demand. Adjusting the overall REE production to optimise the REE producer's operational margins will create surpluses of some REEs and shortages of other REEs. Shortages of a minor constituent lead to dramatic price increases of this REE due to its (very) high price inelasticity. Preferentially, the REE market is driven by the demand for elements that are very abundant (cerium and lanthanum), since this will create less problems with stockpiling of the elements that are available in excess. The unbalanced use of a single REE in a high volume application has to be avoided, especially if this element has a low natural abundance, because this will cause a serious imbalance of the market. There are different solutions that can help to alleviate the balance problem. These will be each discussed in some detail. Since the REE markets are rapidly changing, it is very difficult to extrapolate the future demand of individual REEs on the basis of data for the present demand of these elements. Long-term predictions (for 25 or more years) should be interpreted with caution [13].

\section{Solution 1: Diversification of REE Resources}

At present, the global REE supply is produced from a limited number of ore types: bastnäsite, monazite, xenotime and ion-adsorption clays. Bastnäsite and monazite are rich in LREEs, whereas xenotime and ion-adsorption ores are rich in HREEs and yttrium. The composition of these ores can show some variation from deposit to deposit, but these variations are rather limited. Table 1 gives an overview of the main minerals in REE deposits [14]. New REE deposits contain often less conventional REE minerals such as eudialyte, euxenite, parisite, synchisite, churchite, gadolinite, fergusonite, loparite and steenstrupine.

Phosphate rocks (mainly apatite) used for the production of phosphoric acid and phosphate fertilisers are an important potential REE resource, and were already used in the past for the recovery of REEs [15]. Even though phosphate rocks contain only small REE concentrations, the excavated volumes are enormous.

By combining the REE concentrates obtained from different REE resources, it is possible to compose a mixed concentrate with a composition that is reflecting much better the needs of the individual REEs by the market than in the case when only one single or just a few types of REE ores are used. By combining the REE concentrates from different ores, it is also possible to create a mixed REE feed solution of constant composition. This is beneficial for the optimisation of solvent extraction processes for the separation of mixtures of REEs.
A complementary diversification strategy is to valorise (see top part in Fig. 1) previously landfilled stocks and freshly produced flows of rare-earth-containing industrial process residues [16]. In general, although these secondary resources typically contain much lower REE concentrations with respect to end-of-life consumer goods (see Solution 3), the volumes of these residues are enormous so that the total amounts of rare earths locked in these residues are also very large and may secure an independent source of rare earths as well as shield REE resource-poor countries from export quotas and price fluctuations. These secondary resources include residues from both primary and secondary metal production (as shown in Fig. 1) - phosphogypsum, bauxite residue (red mud), mine tailings, metallurgical slags-and industrial process residues from thermal treatment facilities (coal ash, incinerator ash). As previously shown by the authors, the most promising resources are bauxite residue and phosphogypsum [16]. Bauxite residue (red mud) is a by-product of the aluminium production and is quite rich in scandium [17], whereas phosphogypsum is a by-product of the phosphoric acid production from phosphate rocks [16]. Table 2 provides an overview of typical REE concentrations in these secondary resources [18, 19]. Through the development of (zerowaste) flow sheets for the recovery of REE metals from these large volume streams, it is possible to partially mitigate the balance problem, in a similar way as is the case by combining various primary ores.

\section{Solution 2: Recycling}

Recycling and closing the materials loop are very important activities for bringing the REE markets in balance [20, 21]. As shown in the bottom part of Fig. 1, different forms of recycling can be distinguished. The first type involves the direct (preconsumer) recycling of REE-rich metal scrap and swarf generated during the production of REE-based (intermediate) products (as for instance $\mathrm{NdFeB}$ or $\mathrm{SmCo}$ magnets). Concurrently, the (postconsumer) recycling and/ or urban mining of, respectively, flows and stocks of complex, multi-material, REE-containing products (as for instance a hybrid electric vehicle) and the landfill mining of REE-rich historic urban solid waste can deliver additional REE streams [22].

Volume-wise it is especially the recycling of end-of-life REE-based products that can help addressing the balance problem. Indeed, recycling of neodymium and dysprosium from end-of-life $\mathrm{NdFeB}$ magnets implicates that, all other things being equal, less primary REE ores have to be excavated to meet the global demand of neodymium and dysprosium. Less mining of REE ores implies less overproduction of cerium and samarium. Additionally, recycling of europium, terbium and yttrium from lamp 
Table 1 Typical REE minerals, their chemical formula and total REE content (expressed as total rare-earth oxide, REO)

\begin{tabular}{|c|c|c|}
\hline Mineral & Chemical formula & Total REO (wt\%) \\
\hline Bastnäsite & $\mathrm{REECO}_{3} \mathrm{~F}$ & $53-79$ \\
\hline Monazite & $(\mathrm{REE}, \mathrm{Th}) \mathrm{PO}_{4}$ & $38-71$ \\
\hline Xenotime & $\mathrm{YPO}_{4}$ & $43-65$ \\
\hline Eudialyte & $\mathrm{Na}_{15} \mathrm{Ca}_{6}(\mathrm{Fe}, \mathrm{Mn})_{3} \mathrm{Zr}_{3}(\mathrm{Si}, \mathrm{Nb}, \mathrm{REE}) \mathrm{Si}_{25} \mathrm{O}_{73}\left(\mathrm{OH}, \mathrm{Cl}, \mathrm{H}_{2} \mathrm{O}\right)_{5}$ & $<10$ \\
\hline Euxenite & $(\mathrm{REE}, \mathrm{Ca}, \mathrm{U}, \mathrm{Th})(\mathrm{Nb}, \mathrm{Ta}, \mathrm{Ti})_{2} \mathrm{O}_{6}$ & $<30$ \\
\hline Churchite & $\mathrm{REEPO}_{4} \cdot 2 \mathrm{H}_{2} \mathrm{O}$ & $43-56$ \\
\hline Fergusonite & $(\mathrm{REE}, \mathrm{Th})(\mathrm{Nb}, \mathrm{Ta}, \mathrm{Ti}) \mathrm{O}_{4}$ & $43-52$ \\
\hline Gadolinite & $\mathrm{REEFeBe}_{2} \mathrm{Si}_{2} \mathrm{O}_{10}$ & $<52$ \\
\hline Loparite & $(\mathrm{Na}, \mathrm{REE}, \mathrm{Ca})(\mathrm{Ti}, \mathrm{Nb}) \mathrm{O}_{3}$ & $28-38$ \\
\hline Parisite & $\mathrm{CaREE}_{2}\left(\mathrm{CO}_{3}\right)_{3} \mathrm{~F}_{2}$ & $58-63$ \\
\hline Steenstrupine & $\mathrm{Na}_{14} \mathrm{REE}_{6} \mathrm{Mn}_{2} \mathrm{Fe}_{2}(\mathrm{Zr}, \mathrm{Th}, \mathrm{U})\left(\mathrm{PO}_{4}\right)_{7} \mathrm{Si}_{12} \mathrm{O}_{36}(\mathrm{OH})_{2} \cdot 3 \mathrm{H}_{2} \mathrm{O}$ & $<31$ \\
\hline Synchisite & $\mathrm{CaREE}\left(\mathrm{CO}_{3}\right)_{2} \mathrm{~F}$ & $48-52$ \\
\hline
\end{tabular}

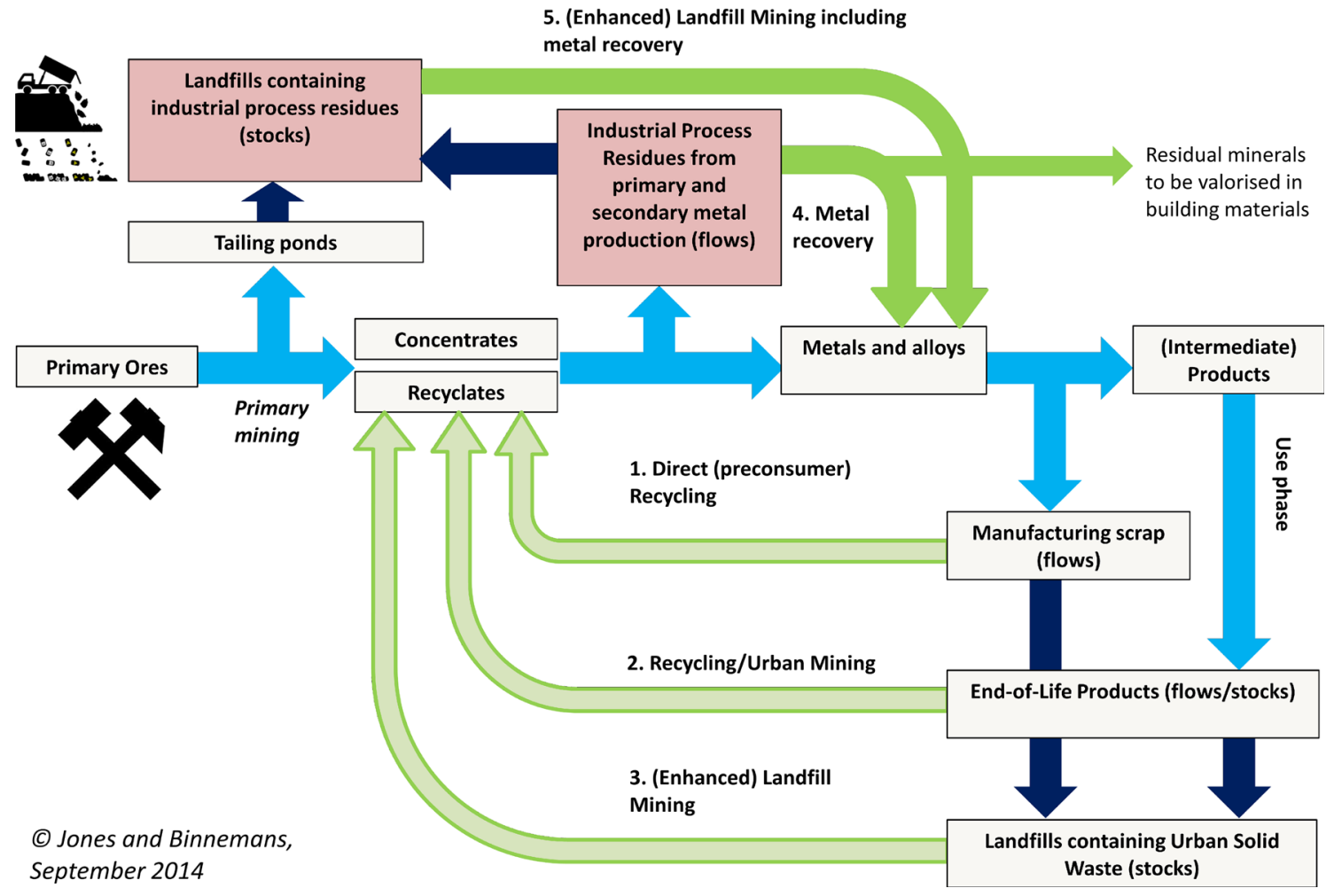

Fig. 1 Recycling of REE-containing resources can take many forms, from mining of primary ores, to direct (preconsumer) recycling, recycling, urban mining and landfill mining of end-of-life products, to

phosphors also helps to keep the HREE market into balance [23]. Thus, by recycling REEs that are essential for high-volume applications, an oversupply of REEs that are less in demand can be avoided. The REE concentrate obtained by recovery of REEs from end-of-life consumer products can be used to adjust the composition of the feed of solvent extraction batteries. Recycling is industrially relevant for the most valuable applications: permanent magnets, lamp phosphors and NiMH batteries. However, the REE recovery from REE containing tailings and fresh/landfilled industrial residues generated during primary and secondary metal production

several challenges remain to be solved, especially the recovery of permanent magnets from shredded waste [24, 25].

To estimate the possible impact of recycling on the REE markets, it is of importance to get a clear idea of the global inventory of the different REEs in use, of the life cycle of REEs in various applications and of the life span of REEcontaining devices. Recently, several research groups started to address this issue [13, 26-31]. Recycling of ceria 
Table 2 Typical REE content of industrial process residues (in ppm)

\begin{tabular}{lll}
\hline REE & Phosphogypsum [18] & Bauxite residue (red mud) [19] \\
\hline $\mathrm{La}$ & 1,450 & 149.0 \\
$\mathrm{Ce}$ & 2,310 & 418.0 \\
$\mathrm{Pr}$ & 235 & 25.8 \\
$\mathrm{Nd}$ & 899 & 115.0 \\
$\mathrm{Sm}$ & 163 & 28.9 \\
$\mathrm{Eu}$ & 34.9 & 5.0 \\
$\mathrm{Gd}$ & 98.7 & 23.3 \\
$\mathrm{~Tb}$ & 7.45 & $\mathrm{n} . \mathrm{d}$ \\
$\mathrm{Dy}$ & 45.5 & 12.8 \\
$\mathrm{Ho}$ & 7.37 & 4.3 \\
$\mathrm{Er}$ & 15.7 & 17.2 \\
$\mathrm{Tm}$ & 1.36 & n.d. \\
$\mathrm{Yb}$ & 5.6 & 15.6 \\
$\mathrm{Lu}$ & 0.568 & 2.4 \\
$\mathrm{Y}$ & 180 & 93.9 \\
$\mathrm{Sc}$ & 1.21 & 127.9 \\
\hline
\end{tabular}

(from polishing powders and car exhaust catalysts) could be recommended from a sustainability point of view, but it will-in contrast to permanent magnets and lamp phosphors-not help to solve the balance problem due to the oversupply of cerium on the market [32].

\section{Solution 3: Substitution}

One type of substitution involves the replacement of one REE element by another one in a given application. However, the different REEs have very different electronic and magnetic properties so that one REE cannot simply be replaced by another REE in the same application. For instance, europium is the only REE that can be used in red lamp phosphors. In fact, europium is unique for its line emission in the red spectral region. In this case, substitution of europium by another REE is not an option. In other cases a more critical REE can be replaced by a less critical one or, even better, by a non-critical REE. The NdFeB magnets are a good example of an application where this type of substitution can play a role [9]. Part of the neodymium (up to $25 \%$ ) can be replaced by praseodymium without significantly changing the magnetic properties of the material. This is a very good opportunity to consume a large part of the praseodymium supply (which is less abundant than neodymium, but has also less specific applications) and to help bringing the LREE market in balance. This also means that there is no need to use very high purity neodymium in $\mathrm{NdFeB}$ magnets; didymium (the old name used for the mixture of neodymium and praseodymium) can be used as well. However, it is not possible to replace part of the neodymium in $\mathrm{NdFeB}$ magnets by samarium. Part of the dysprosium in $\mathrm{NdFeB}$ magnets can be replaced by terbium. This is not often done at present because terbium is a very critical element due to its use in the green lamp phosphors. However, it can be anticipated that more terbium will become available for use in $\mathrm{NdFeB}$ magnets, as it is expected that the fluorescent lamps will increasingly be replaced by LEDs (vide supra).

What about the replacement of neodymium-iron-boron magnets by samarium-cobalt magnets? As described above, SmCo magnets are in use for a longer time than the $\mathrm{NdFeB}$ magnets and for a long time samarium was the most critical REE element in so far that the production of SmCo magnets was limited by shortages in the supply of samarium, with very high samarium prices as a result. However, after 1985 SmCo magnets have been rapidly replaced by $\mathrm{NdFeB}$ magnets. $\mathrm{NdFeB}$ magnets have a higher energy density than SmCo magnets, but, more importantly, NdFeB magnets are less expensive than $\mathrm{SmCo}$ magnets. More than $70 \%$ of the mass of $\mathrm{NdFeB}$ magnets consists of cheap iron, while the natural abundance of neodymium is much higher than that of samarium. Furthermore, the SmCo magnets contain also the rather expensive cobalt. SmCo magnets have some advantages compared to $\mathrm{NdFeB}$ magnets: they are much more resistant to demagnetisation at higher temperatures and they are much more resistant to corrosion (SmCo magnets do not need to be coated by an anticorrosion layer, in contrast to $\mathrm{NdFeB}$ magnets). Therefore, SmCo magnets are used in high temperature applications and in applications where corrosion can be an issue. Typical markets for $\mathrm{SmCo}$ magnets are the aircraft industry and the military industry. Still, the market of SmCo magnets is very small compared to the huge market of $\mathrm{NdFeB}$ magnets. As indicated above, the share of SmCo magnets in the permanent magnet market is less than $2 \%$. Given the criticality of neodymium/dysprosium and the oversupply of samarium, one can ask the question why no larger quantities of SmCo magnets are produced? The reason for this is twofold. First of all, as discussed above, SmCo magnets are more expensive than $\mathrm{NdFeB}$ magnets due to the large quantities of cobalt they contain. Cobalt has suffered from its own supply risks in the past and it is a rather expensive element. Cobalt is also used in lithium-ion-batteries, in the form of lithium cobalt oxide $\left(\mathrm{LiCoO}_{2}\right)$ in cathode materials. Secondly, the safety regulations for working with samarium in an industrial environment have become more strict. Samarium has two naturally occurring radioisotopes, which are long-lived $\alpha$ emitters: ${ }^{147} \mathrm{Sm}\left(t_{1 / 2}=1.07 \times 10^{11}\right.$ years; natural abundance $=15.01 \%)$ and ${ }^{148} \mathrm{Sm}\left(t_{1 / 2}=7 \times 10^{15}\right.$ years; natural abundance $=11.22 \%)[33,34]$. Working with bulk samples such as in SmCo magnets or with samariumcontaining solutions is not a problem, but working with $\mathrm{Sm}_{2} \mathrm{O}_{3}$ powder (which is a precursor for samarium alloys) 
is restricted by safety regulations due to the dangers associated with possible inhalation of powders of $\alpha$-emitters. Nevertheless, SmCo magnets have some untapped potential for use in high-end applications that require strong magnets that remain operational at high temperatures and that have a good resistance against corrosion. For example, hybrid and full electric vehicles could make use of SmCo magnets in the drive and stop-start motors.

Substitution can also mean replacement of REEs by non-REEs, even though this can lead to products with poor, yet still acceptable, performance. Examples include fluid cracking catalysts based on zeolites without REEs. NdFeB or SmCo magnets can be replaced by ferrite or alnico magnets, but these magnets have much lower energy densities. Therefore, REE magnets are unlikely to be replaced in applications where miniaturisation is of importance. Major research efforts are directed to the development of cerium-based magnetic materials. Until 1975, mischmetal was often used for nodularising graphite in cast iron and for desulphurising steel, but these metallurgical applications became largely obsolete due to better production methods and replacement of mischmetal by calcium or magnesium [35]. Ceria in polishing materials could be replaced by alumina or iron oxide, but this is at present not a favourable option since there is an oversupply of cerium. NiMH batteries, containing large quantities of LREEs and especially lanthanum, could be replaced by lithium-ion batteries. Likewise, the $\mathrm{LaNi}_{5}$ alloy in $\mathrm{NiMH}$ batteries could be replaced by a REE-free titanium-iron alloy. However, there is little incentive to replace rare earths in polishing powder and NiMH batteries because cerium and lanthanum are so cheap and abundant.

Sometimes, substitution can be more than simply replacing one element by another. Indeed a more radical form of substitution takes place when a totally new technology is introduced to the market, making the older technology based on REEs obsolete. Until about 10-15 years ago, europium was an important component of red cathodoluminescent phosphors used in cathode-ray tubes (CRTs) for colour television screens and computer monitors. The CRTs screens were replaced by plasma displays (still containing REE phosphors) and LCD screens (using REEs in the phosphors of the backlight fluorescent lamps), but modern OLED screens do not contain REEs at all. A similar evolution is taking place by the replacement of fluorescent lamps by LEDs.

\section{Solution 4: Reduced Use}

By clever engineering, it is possible to reduce the consumption of critical REEs in a given application, without compromising the performance of the REE-containing devices. The $\mathrm{NdFeB}$ magnets, which contain dysprosium to protect the magnetic material against demagnetisation at higher temperatures, are a good example. By grain boundary diffusion, the dysprosium is concentrated near the grain boundaries of a sintered $\mathrm{NdFeB}$ magnet [36-38]. As a consequence the required total dysprosium concentration can be decreased by more than $50 \%$. It is even possible to make dysprosium-free $\mathrm{NdFeB}$ magnets for use in electric motors [39-41].

It is important not to waste critical REEs in applications that do not require purified REEs. In the past, no efforts were made to remove neodymium from the concentrate that was used to prepare mischmetal, although the presence of neodymium was not essential for applications of mischmetal. At present, neodymium is very valuable (e.g. for use in permanent magnets) and is, therefore, removed prior to mischmetal production.

\section{Solution 5: New High-Volume Applications}

Compared to the other REEs, lanthanum and especially cerium are very abundant and cheap. For western REE mining companies, the lanthanum and cerium content of their ores often have a negative effect on the REE basket value and, subsequently, these elements are a nuisance for these companies, who look for new separation technologies that can deliver a lanthanum- and cerium-free concentrate. The oversupply of lanthanum and cerium can be partially overcome by developing new high-volume applications for these elements. Research in this area must be encouraged. An example of an emerging high-volume low-tech application is the use of chlorides of lanthanum, cerium or mixtures thereof in water purification technology for removal of dissolved phosphate ions from water. The trivalent REE ions have a high affinity for phosphate ions, resulting in the formation of poorly soluble and readily filterable REE phosphates. This application is commercialized by Molycorp (SorbX-100 ${ }^{\circledR}$ and PhosFIX ${ }^{\circledR}$ ). Cerium is being investigated as active component in redox flow batteries, for instance the zinc-cerium redox flow battery [42]. Other applications of cerium include [43, 44]: use for the destructive total oxidation of toxic organic compounds [45, 46], as a redox mediator in organic electrosynthesis [47], as photocatalyst [48] or to enhance the photocatalytic activity of titanium oxide [44, 49]. Another new application of rare earths is in perovskites for use as electrocatalysts in lithium-air batteries [50-52]. However, an important new high-volume application of lanthanum and cerium is as thermal stabiliser of PVC [53-57]. Stabilisers are added to PVC to protect the polymer against thermal decomposition during processing at temperatures above $200{ }^{\circ} \mathrm{C}$, and to protect PVC against heat and UV irradiation during use. At present lead, cadmium, zinc, tin, barium and calcium salts are added as stabilisers to PVC. 
The use of lead and cadmium stabilisers is phased-out in many countries due to toxicity issues. The safest of the presently used stabilisers are the calcium and zinc salts. Lanthanum and cerium salts (for instance stearates or other salts of fatty acids) have a stronger stabilising effect on PVC than calcium and zinc salts at the same dose. About $3 \mathrm{~kg}$ of rare-earth stabilisers can be added to 1 tonne of PVC. Given the very large volumes of PVC produced globally each year ( $>40$ million of tonnes), it is evident that the PVC industry could be a very large consumer of (light) rare earths.

\section{Thorium}

The thorium issue is related to the balance problem as well. Nearly all REE ores contain the radioactive elements thorium and uranium. Although the uranium content of typical REE ores is low, the thorium content of some REE ores is rather high. For instance, monazite can contain more than $15 \mathrm{wt} \%$ of $\mathrm{ThO}_{2}[58,59]$. Natural thorium is a mono-isotopic element: all but some traces of natural thorium consist of the isotope ${ }^{232} \mathrm{Th}$, an $\alpha$-emitter with a half-life of 14.05 billion years. Due to the safety regulations associated with the handling of naturally occurring radioactive materials (NORM), the thorium content of REE ores is a major issue for REE producers [60]. At present, there are no large scale applications of thorium. Furthermore, thorium is considered as radioactive waste and its disposal can be very expensive. The thorium content of monazite is the reason why Rhône-Poulenc (now Solvay) stopped processing monazite at the REE production plant of $\mathrm{La}$ Rochelle in France in 1994. The thorium content of the REE ore of Bayan Obo is causing environmental issues in Baotou (PR China) [61]. As long as thorium is considered as radioactive waste, it will increase the production costs of the rare earths. The costs of thorium waste disposal need to be shared by the different REE applications. However, thorium could be used as a nuclear fuel instead of uranium. Thorium can be used in conventional light-water nuclear reactors, although in that case $\mathrm{ThO}_{2}$ has to be mixed with plutonium oxide [62]. Canadian CANDU reactors can burn thorium as well [63]. A much better approach is to use specially designed nuclear reactors such as the molten salt thorium reactor, which do not need the use of plutonium [64]. Interestingly, in the past the REEs were by-products of thorium production. Thorium was used at the end of the nineteenth century and the first half of the twentieth century to prepare incandescent gas mantles (99\% $\mathrm{ThO}_{2}+1 \% \mathrm{CeO}_{2}$ ) and the REEs were considered more or less as a waste product, although there were some applications for cerium and mischmetal. Contrastingly, at present thorium is considered as a dangerous waste product. However, the transition to a thorium-based nuclear fuel cycle could lead to zero-waste valorisation of thorium-containing REE ores, so that both REEs and thorium can be considered as valuable resources. In case that nuclear power plants burning thorium fuel will become operational in the future, no thorium mines need to be opened, since the quantity of thorium obtained through processing of monazite and other thorium-containing REE minerals will probably be sufficient to cover the future global demand of thorium.

\section{Conclusions}

The balance problem is an intrinsic problem of REE markets and is caused by the imbalance between the demand of individual REEs and their natural abundance in REE ores. Keeping the REE markets in balance is of strategic importance, not only to secure the supply of all REEs required for technological and other applications, but also to avoid dramatic price shocks for critical REEs. Different solutions have been proposed to solve the balance problem: diversification of REE primary ore and secondary process residues, recycling, substitution, reduced use and new highvolume applications. There is no straightforward solution for this issue. However, by combining different strategies the balance problem can be mitigated. It was shown that the presence of thorium in most of the REE ores is also related to the balance problem: thorium is now considered as an expensive radioactive waste, but this waste could be turned into a resource by using thorium in a thorium-based nuclear fuel cycle. Finally, it is crucial to stress that at present there is too much focus on the figures with respect to the total REE ore reserves and/or the total REOs production numbers. It must be realised that most of the current high-tech applications of REEs require the use of purified individual REEs rather than mixtures of REEs. Therefore, It cannot be emphasised enough how important it is to effectively deal with the balance problem.

Acknowledgments The authors thank KU Leuven for financial support (projects GOA/13/008 and IOF-KP RARE ${ }^{3}$ ).

\section{References}

1. Haxel GB, Hedrick JB, Orris GJ (2002) Rare earth elementscritical resources for high technology: U.S. geological survey fact sheet 087-02. http://geopubs.wr.usgs.gov/fact-sheet/fs087-02/

2. Brobst DA, Pratt WP (1973) United States mineral resources, USGS Professional Paper: 820. United States Government Printing Office, Washington DC

3. Binnemans K, Jones PT, Van Acker K, Blanpain B, Mishra B, Apelian D (2013) Rare-earth economics: the balance problem. JOM 65:846-848 
4. Falconnet P (1985) The economics of rare-earths. J Less-Common Met 111:9-15

5. Falconnet P (1989) Industrial strategy and ecomomics of rare earths. Proceedings of the first workshop on the basic and applied aspects of rare earths (Venice, Italy, 26-27th May, 1988), pp 19-31

6. Goonan TG (2011) Rare earth elements - end use and recyclability: U.S. geological survey scientific investigations report 2011-5094, p 15. http://pubs.usgs.gov/sir/2011/5094/

7. Gschneidner KA, Pecharsky VK (2000) Magnetocaloric materials. Annu Rev Mater Sci 30:387-429

8. Gschneidner KA, Pecharsky VK (2006) Rare earths and magnetic refrigeration. J Rare Earths 24:641-647

9. Gutfleisch O, Willard MA, Bruck E, Chen CH, Sankar SG, Liu JP (2011) Magnetic materials and devices for the 21st century: stronger, lighter, and more energy efficient. Adv Mater 23:821-842

10. Ronda CR (1995) Phosphors for lamps and displays-an applicational view. J Alloys Compd 225:534-538

11. Ye S, Xiao F, Pan YX, Ma YY, Zhang QY (2010) Phosphors in phosphor-converted white light-emitting diodes recent advances in materials, techniques and properties. Mater Sci Eng R-Rep 71:1-34

12. Acuna P, Leyre S, Audenaert J, Meuret Y, Deconinck G, Hanselaer P (2014) Power and photon budget of a remote phosphor LED module. Opt Express 22:A1079-A1092

13. Alonso E, Sherman AM, Wallington TJ, Everson MP, Field FR, Roth R, Kirchain RE (2012) Evaluating rare earth element availability: a case with revolutionary demand from clean technologies. Environ Sci Technol 46:3406-3414

14. Chakhmouradian AR, Wall F (2012) Rare earth elements: minerals, mines, magnets (and more). Elements 8:333-340

15. Habashi $F(1985)$ The recovery of the lanthanides from phosphate rock. J Chem Technol Biot A 35:5-14

16. Binnemans K, Pontikes Y, Jones PT, Van Gerven T, Blanpain B (2013c) Recovery of rare earths from industrial waste residues: a concise review. Proceedings of the third international slag valorisation symposium (19-20 March 2013, Leuven, Belgium), pp 191-205

17. Ochsenkühn-Petropoulou MT, Hatzilyberis KS, Mendrinos LN, Salmas CE (2002) Pilot-plant investigation of the leaching process for the recovery of scandium from red mud. Ind Eng Chem Res 41:5794-5801

18. Germeau A, Guidi T, Fati D (2013) Method for treating phosphate rock. Patent WO 2013060689 A1

19. Ochsenkühn-Petropoulou M, Lyberopulu T, Parissakis G (1994) Direct determination of lanthanides, yttrium and scandium in bauxites and red mud from alumina production. Anal Chim Acta 296:305-313

20. Binnemans K, Jones PT, Blanpain B, Van Gerven T, Yang YX, Walton A, Buchert M (2013) Recycling of rare earths: a critical review. J Clean Prod 51:1-22

21. Tanaka M, Oki T, Koyama K, Narita H, and Oishi T (2013) Recycling of rare earths from scrap. In: Bünzli J-CG, Pecharsky VK (eds) Handbook on the physics and chemistry of rare earths, vol 43, Chapter 255. Elsevier, Amsterdam, pp 159-212

22. Jones PT, Geysen D, Tielemans Y, Van Passel S, Pontikes Y, Blanpain B, Quaghebeur M, Hoekstra N (2013) Enhanced landfill mining in view of multiple resource recovery: a critical review. J Clean Prod 55:45-55

23. Binnemans K, Jones PT (2014) Perspectives for the recovery of rare earths from end-of-life fluorescent lamps. J Rare Earths 32:195-200

24. Bandara HMD, Darcy JW, Apelian D, Emmert MH (2014) Value analysis of neodymium content in shredder feed: toward enabling the feasibility of rare earth magnet recycling. Environ Sci Technol 48:6553-6560
25. Darcy JW, Bandara HMD, Mishra B, Blanplain B, Apelian D, Emmert MH (2013) Challenges in recycling end-of-life rare earth magnets. JOM 65:1381-1382

26. Du XY, Graedel TE (2011) Global in-use stocks of the rare earth elements: a first estimate. Environ Sci Technol 45:4096-4101

27. Du XY, Graedel TE (2011) Global rare earth in-use stocks in $\mathrm{NdFeB}$ permanent magnets. J Ind Ecol 15:836-843

28. Du XY, Graedel TE (2011c) Uncovering the global life cycles of the rare earth elements. Sci Rep 1: Article Number: 145

29. Du XY, Graedel TE (2013) Uncovering the end uses of the rare earth elements. Sci Total Environ 461:781-784

30. Nansai K, Nakajima K, Kagawa S, Kondo Y, Suh S, Shigetomi Y, Oshita Y (2014) Global flows of critical metals necessary for low-carbon technologies: the case of neodymium, cobalt, and platinum. Environ Sci Technol 48:1391-1400

31. Rademaker JH, Kleijn R, Yang YX (2013) Recycling as a strategy against rare earth element criticality: a systemic evaluation of the potential yield of ndfeb magnet recycling. Environ Sci Technol 47:10129-10136

32. Biswas DI (2013) Potential for recovery of cerium contained in automotive catalytic converters: U.S. Geological Survey OpenFile Report 2013-1037, p 10. http://pubs.usgs.gov/of/2013/1037

33. Gupta MC, Macfarla RD (1970) Natural alpha radioactivity of samarium. J Inorg Nucl Chem 32:3425-3432

34. Kossert K, Jorg G, Nahle O, Gostomski CLV (2009) High-precision measurement of the half-life of Sm-147. Appl Radiat Isot 67:1702-1706

35. Nagai H (1998) Rare earths in steels. In: Gschneidner Jr KA and Eyring L (eds) Handbook on the physics and chemistry of rare earths, vol 25, Chapter 65. Elsevier, Amsterdam, pp 1-49

36. Cui WB, Takahashi YK, Hono K (2011) Microstructure optimization to achieve high coercivity in anisotropic $\mathrm{Nd}-\mathrm{Fe}-\mathrm{B}$ thin films. Acta Mater 59:7768-7775

37. Sepehri-Amin H, Une Y, Ohkubo T, Hono K, Sagawa M (2011) Microstructure of fine-grained $\mathrm{Nd}-\mathrm{Fe}-\mathrm{B}$ sintered magnets with high coercivity. Scr Mater 65:396-399

38. Sepehri-Amin H, Ohkubo T, Shima T, Hono K (2012) Grain boundary and interface chemistry of an $\mathrm{Nd}-\mathrm{Fe}-\mathrm{B}$-based sintered magnet. Acta Mater 60:819-830

39. Brown DN, Wu Z, He F, Miller DJ, Herchenroeder JW (2014) Dysprosium-free melt-spun permanent magnets. J Phys Condens Matter 26: Article Number: 064202

40. Goto R, Matsuura M, Sugimoto S, Tezuka N, Une Y, Sagawa M (2012) Microstructure evaluation for Dy-free Nd-Fe-B sintered magnets with high coercivity. J Appl Phys 111: Article Number: 07A739

41. Kobayashi K, Urushibata K, Une Y, Sagawa M (2013) The origin of coercivity enhancement in newly prepared high coercivity Dyfree Nd-Fe-B sintered magnets. J Appl Phys 113: Article Number: 163910

42. Leung PK, Ponce-de-Leon C, Low CTJ, Shah AA, Walsh FC (2011) Characterization of a zinc-cerium flow battery. J Power Sources 196:5174-5185

43. Binnemans K (2006) Applications of tetravalent cerium compounds. In: Gschneidner Jr KA, Bünzli J-CG, and Pecharsky VK (eds) Handbook on the physics and chemistry of rare earths, vol 36, Chapter 229. Elsevier, Amsterdam, pp 281-392

44. Trovarelli A, de Leitenburg C, Boaro M, Dolcetti G (1999) The utilization of ceria in industrial catalysis. Catal Today 50: 353-367

45. Balaji S, Chung SJ, Ryu JY, Moon IS (2009) Destruction of commercial pesticides by cerium redox couple mediated electrochemical oxidation process in continuous feed mode. J Hazard Mater 172:1470-1475

46. Kokovkin VV, Chung SJ, Balaji S, Matheswaran M, Moon IS (2007) Electrochemical cell current requirements for toxic 
organic waste destruction in Ce(IV)-mediated electrochemical oxidation process. Korean J Chem Eng 24:749-756

47. Devadoss V, Basha CA, Jayaraman K (2008) Indirect electrochemical oxidation of p-methoxy-toluene to p-methoxy-benzaldehyde using ceric methanesulphonate: a scale-up study. Ind Eng Chem Res 47:4607-4616

48. Reddy JK, Suresh G, Hymavathi CH, Kumari VD, Subrahmanyam M (2009) Ce (III) species supported zeolites as novel photocatalysts for hydrogen production from water. Catal Today 141:89-93

49. Kozlova EA, Korobkina TP, Vorontsov AV (2009) Overall water splitting over $\mathrm{Pt} / \mathrm{TiO}_{2}$ Catalyst with $\mathrm{Ce}^{3+} / \mathrm{Ce}^{4+}$ shuttle charge transfer system. Int J Hydrogen Energy 34:138-146

50. Hardin WG, Slanac DA, Wang X, Dai S, Johnston KP, Stevenson KJ (2013) Highly active, nonprecious metal perovskite electrocatalysts for bifunctional metal-air battery electrodes. J Phys Chem Lett 4:1254-1259

51. Jung KN, Jung JH, Im WB, Yoon S, Shin KH, Lee JW (2013) Doped lanthanum nickelates with a layered perovskite structure as bifunctional cathode catalysts for rechargeable metal-air batteries. ACS Appl Mater Interfaces 5:9902-9907

52. Kalubarme RS, Park GE, Jung KN, Shin KH, Ryu WH, Park CJ (2014) $\mathrm{LaNi}_{\mathrm{x}} \mathrm{Co}_{1-\mathrm{x}} \mathrm{O}_{3-\delta}$ perovskites as catalyst material for nonaqueous lithium-oxygen batteries. J Electrochem Soc 161:A880A889

53. Fan WX, Chen G, Wan SK, Su QD (1999) Spectral studies on the mechanism of rare earth poly (vinyl chloride) thermal stabilizers. Spectrosc Spec Anal 19:772-775
54. Jiang ZY, Li M, Liu ZG, Hu YH, Wang MT, Wang H (2013) Influence of rare-earth thermal stabilizers on polyvinyl chloride. Plast Res Online. doi:10.2417/spepro.004600

55. Li M, Jiang ZY, Liu ZG, Hu YH, Wang MT, Wang HO (2013) Effect of lanthanum cyanurate as novel organic thermal stabilizers for polyvinyl chloride. Polym Eng Sci 53:1706-1711

56. Peng ZB, Hu B, Su QD, Qu JZ (2003) Study on mechanism of rare earth PVC stabilizer. J Rare Earths 21:328-330

57. Zheng YY, Cai WL, Fu ML, Wang CY, Zhang X (2005) Rare earth stearates as thermal stabilizers for rigid poly(vinyl chloride). J Rare Earths 23:172-177

58. Murata KJ, Rose J, Carron MK (1953) Systematic variation of rare earths in monazite. Geochim Cosmochim Acta 4:292-300

59. Murata KJ, Rose J, Carron MK, Glass JJ (1957) Systematic variation of rare-earth elements in cerium-earth minerals. Geochim Cosmochim Acta 11:141-161

60. Golev A, Scott M, Erskine PD, Ali SH, Ballantyne GR (2014) Rare earths supply chains: current status, constraints and opportunities. Res Policy 41:52-59

61. Guo P, Jia X, Duan T, Xu J, Chen H (2010) Influence of plant activity and phosphates on thorium bioavailability in soils from Baotou area, Inner Mongolia. J Environ Radioact 101:767-772

62. Kamei T, Hakami S (2011) Evaluation of implementation of thorium fuel cycle with LWR and MSR. Prog Nucl Energy 53:820-824

63. Jeong CJ, Park CJ, Ko WI (2008) Dynamic analysis of a thorium fuel cycle in CANDU reactors. Ann Nucl Energy 35:1842-1848

64. Furukawa K, Mitachi K, Kato Y (1992) Small molten-salt reactors with a rational thorium fuel-cycle. Nucl Eng Des 136:157-165 